University of Nebraska - Lincoln

DigitalCommons@University of Nebraska - Lincoln

\title{
Unimolecular Decomposition of 5-Aminotetrazole and its Tautomer 5-Iminotetrazole: New Insight from Isopotential Searching
}

Kristian W. Paul

U.S. Army Research Laboratory, Aberdeen ProVing Ground, Maryland

Margaret M. Hurley

Karl K. Irikura

Follow this and additional works at: https://digitalcommons.unl.edu/usarmyresearch

Part of the Operations Research, Systems Engineering and Industrial Engineering Commons

Paul, Kristian W.; Hurley, Margaret M.; and Irikura, Karl K., "Unimolecular Decomposition of 5-Aminotetrazole and its Tautomer 5-Iminotetrazole: New Insight from Isopotential Searching" (2009). US Army Research. 27.

https://digitalcommons.unl.edu/usarmyresearch/27

This Article is brought to you for free and open access by the U.S. Department of Defense at DigitalCommons@University of Nebraska - Lincoln. It has been accepted for inclusion in US Army Research by an authorized administrator of DigitalCommons@University of Nebraska - Lincoln. 


\title{
Unimolecular Decomposition of 5-Aminotetrazole and its Tautomer 5-Iminotetrazole: New Insight from Isopotential Searching
}

\author{
Kristian W. Paul,*,»» Margaret M. Hurley, ${ }^{*, \dagger}$ and Karl K. Irikura ${ }^{\ddagger}$ \\ U.S. Army Research Laboratory, Aberdeen Proving Ground, Maryland 21005-5069, and Computational \\ Chemistry Group, National Institute of Standards and Technology, Gaithersburg, Maryland 20899-8320
}

Received: November 25, 2008; Revised Manuscript Received: January 12, 2009

\begin{abstract}
Aminotetrazole compounds have become attractive ingredients in gas generating compositions, solid rocket propellants, and green pyrotechnics. Therefore, a fundamental understanding of their thermal decomposition mechanisms and thermodynamics is of great interest. In this study, the specular reflection isopotential searching method was used to investigate the unimolecular decomposition mechanisms of 5-iminotetrazole (5-ITZ), $1 H$-5-aminotetrazole ( $1 H$-5-ATZ), and $2 H$-5-aminotetrazole ( $2 H$-5-ATZ). Subsequent thermochemical analysis of the unimolecular decomposition pathways was performed at the CCSD(T)/aug-cc-pVTZ//B3LYP/6$311++\mathrm{G}(3 \mathrm{df}, 3 \mathrm{pd})$ level of theory. Based upon the relative reaction barriers predicted in this study, the initial gaseous products of 5-ITZ unimolecular decomposition are $\mathrm{HN}_{3}$ and $\mathrm{NH}_{2} \mathrm{CN}$ (calculated activation barrier equal to $199.5 \mathrm{~kJ} / \mathrm{mol})$. On the other hand, the initial gaseous products of $1 H-5-\mathrm{ATZ}$ and $2 \mathrm{H}-5-\mathrm{ATZ}$ unimolecular decomposition are predicted to be $\mathrm{N}_{2}$ and metastable $\mathrm{CH}_{3} \mathrm{~N}_{3}$ (calculated activation barriers equal to 169.2 and $153.7 \mathrm{~kJ} / \mathrm{mol}$, respectively). These predicted unimolecular decomposition products and activation barriers are in excellent agreement with thermal decomposition experiments performed by Lesnikovich et al. [Lesnikovich, A. I.; Ivashkevich, O. A.; Levchik, S. V.; Balabanovich, A. I.; Gaponik, P. N.; Kulak, A. A. Thermochim. Acta 2002, 388, 233], in which the apparent activation barriers were measured to be approximately 200 and $150 \mathrm{~kJ} / \mathrm{mol}$, respectively, for 5-ITZ and $1 H$-5-ATZ/2H-5-ATZ.
\end{abstract}

\section{Introduction}

Aminotetrazoles are a novel class of organic compounds that possess a wide range of desirable chemical and physical properties. Aminotetrazoles have the highest nitrogen content of all organic compounds. For example, 5-aminotetrazole (5ATZ) and its tautomer 5-iminotetrazole (5-ITZ) (Figure 1) possess $82.3 \%$ nitrogen by weight. 5-ATZ also exhibits high thermal stability. ${ }^{1}$ Because of its high nitrogen content and thermal stability, 5-ATZ is frequently used as an ingredient in gas generating compositions ${ }^{2-6}$ and solid rocket propellants. ${ }^{7,8}$ In addition, 5-ATZ is now being used as a starting material for the synthesis of green pyrotechnics, which are based upon tetrazole derivatives. ${ }^{9}$

Because of its importance as an ingredient in gas generating compositions and solid rocket propellants, the thermal decomposition of 5-ATZ has been investigated by several experimental groups. Brady ${ }^{10}$ investigated the electron impact-induced fragmentation of 5-ATZ and suggested two routes to decomposition: (1) splitting of 5-ATZ to cyanamide $\left(\mathrm{NH}_{2} \mathrm{CN}\right)$ and hydrogen azide $\left(\mathrm{HN}_{3}\right)$ and (2) elimination of $\mathrm{N}_{2}$ with the formation of a metastable $\mathrm{CH}_{3} \mathrm{~N}_{3}$ product. Reimlinger ${ }^{11}$ observed $\mathrm{HN}_{3}$ in the thermal decomposition of 5-ATZ, but $\mathrm{NH}_{2} \mathrm{CN}$ was not isolated and detected. Using a rapid-scan Fourier transform infrared (FTIR)/temperature profiling method and T-jump/FTIR spectroscopy, Brill and co-workers ${ }^{12,13}$ measured $\mathrm{HN}_{3}$ and $\mathrm{NH}_{2} \mathrm{CN}$ as the initial primary gaseous products of 5-ATZ thermal

* Corresponding authors. (K.W.P.) E-mail: kristian.paul@usa.dupont.com. Telephone: (302)-451-3595. Fax: (302)-451-5941. (M.M.H.) E-mail: hurley@arl.army.mil. Telephone: (410)-306-0728. Fax: (410)-306-1909.

U.S. Army Research Laboratory.

* National Institute of Standards and Technology.

${ }^{\S}$ Current Address: DuPont Crop Protection, Stine-Haskell Research Center, Newark, Delaware 19714-0030.

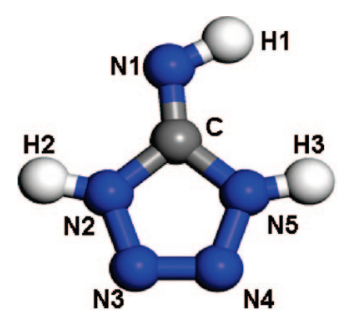

(a)

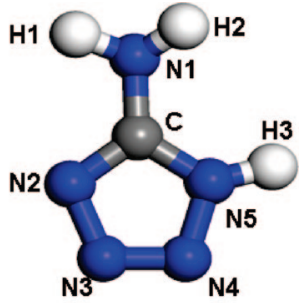

(b)

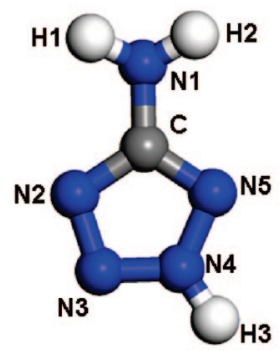

(c)

Figure 1. (a) 5-iminotetrazole, (b) $1 H$-5-aminotetrazole, and (c) $2 H$ 5-aminotetrazole. Atoms are colored as follows: C (gray), $\mathrm{N}$ (blue), and $\mathrm{H}$ (white).

decomposition. Levchik et al. ${ }^{1}$ and Lesnikovich et al. ${ }^{14}$ investigated the thermal decomposition of 5-ATZ, paying close attention to the role of 5-ATZ/5-ITZ tautomerism which had been previously identified in the solid state by vibrational spectroscopy. ${ }^{15,16}$ Levchik et al. ${ }^{1}$ determined that their initial sample of solid 5-ATZ consisted primarily of the imino form, 5-ITZ. However, thermal treatment resulted in an increased proportion of the amino form, 5-ATZ. IR spectroscopy and mass spectrometry showed that 5-ITZ thermal decomposition started 
immediately after melting and resulted in $\mathrm{HN}_{3}$ and carbodiimide $(\mathrm{NHCNH})$, which likely isomerizes into $\mathrm{NH}_{2} \mathrm{CN} .{ }^{1,17}$ Increasing the temperature further led to another thermal decomposition pathway involving 5-ATZ, namely, the formation of $\mathrm{N}_{2}$ and a metastable $\mathrm{CH}_{3} \mathrm{~N}_{3}$ product. ${ }^{1}$ The apparent activation energies for these two thermal decomposition pathways were estimated to be approximately 200 and $150 \mathrm{~kJ} / \mathrm{mol}$, respectively. ${ }^{14}$

Progress has been made in applying computational approaches to elucidating the thermal decomposition mechanisms of substituted tetrazole compounds ${ }^{18}$ and their relative impact sensitivities. ${ }^{19,20}$ Wang et al..$^{18}$ used ab initio molecular dynamics (AIMD) simulations and quantum chemical methods to investigate the decomposition mechanisms of 5-nitro-1- $H$-tetrazole. AIMD simulations revealed three possible unimolecular decomposition pathways that lead to the release of $\mathrm{N}_{2} \cdot{ }^{18} \mathrm{ZhaoXu}$ and co-workers ${ }^{19,20}$ used density functional theory and semiempirical methods to analyze sensitivity and the activation barrier of ring opening for a series of $\mathrm{C}$ - and $\mathrm{N}$-substituted tetrazole compounds, and additionally performed an analysis of the heats of formation of a large series of tetrazole derivatives at the B3LYP level of theory. ${ }^{21}$ Cheng used a variety of quantum chemical methods to investigate the synthesis of tetrazole and the tetrazolate anion. ${ }^{22}$ Zhang et al. ${ }^{23}$ investigated the thermodynamics and kinetics of 5-ATZ unimolecular decomposition, using a variety of quantum chemical methods. Following the experimental work performed by Levchik et al. ${ }^{1}$ and Lesnikovich et al., ${ }^{14}$ Zhang et al. ${ }^{23}$ investigated the formation of $\mathrm{HN}_{3}$ and $\mathrm{NH}_{2} \mathrm{CN}$ resulting from the thermal decomposition of 5-ATZ, but not its tautomer 5-ITZ. Furthermore, Zhang et al. ${ }^{23}$ did not investigate the unimolecular decomposition pathway of 5-ATZ leading to the formation of $\mathrm{N}_{2}$ and a metastable $\mathrm{CH}_{3} \mathrm{~N}_{3}$ product, which had been previously identified experimentally. ${ }^{1,10,14}$ Therefore, a need clearly exists to further investigate the mechanisms and thermodynamics of 5-ATZ and 5-ITZ unimolecular decomposition, using quantum chemical methods.

The objective of this study was to investigate the mechanisms and thermodynamics of the unimolecular decomposition pathways of 5-ATZ and its tautomer 5-ITZ. Both the $1 H$ and $2 H$ tautomers of 5-ATZ were investigated, as the energetics of this tautomerization has been the subject of much debate within the literature. The mechanisms of $1 \mathrm{H}$ - and $2 \mathrm{H}$-5-ATZ and 5-ITZ unimolecular decomposition were revealed by isopotential searching (IPS). IPS methods are suitable for locating lowenergy exit channels from potential energy surface (PES) wells, without foreknowledge of the reaction products. ${ }^{24}$ IPS methods have been successfully applied to both unimolecular and bimolecular reactions..$^{24,25}$ The thermodynamics of 5-ATZ and 5-ITZ unimolecular decomposition pathways were subsequently obtained with standard quantum chemical methods. This study will show that the activation barriers predicted for the unimolecular decomposition pathways of 5-ATZ and 5-ITZ are in very reasonable agreement with previous experimental results.

\section{Computational Methods}

The specular reflection (SR) IPS algorithm developed by Irikura and Johnson ${ }^{24}$ was used to qualitatively explore the PES of 5-ATZ and its tautomer 5-ITZ. In the SR-IPS algorithm, two arbitrary seed points are generated on the isopotential contour of interest. A third point is generated by bouncing the first point off the second point, specularly to the plane defined by the gradient of the energy with respect to the Cartesian nuclear coordinates. This is continued for as many steps as desired. The SR-IPS algorithm is described by eq 1 , where $\vec{x}_{i}$ is the $3 N$ - dimensional coordinate vector at point $i$ and $\vec{g}_{i}$ is the gradient (with respect to Cartesian coordinates) of the energy at point $i$.

$$
\vec{x}_{i+1}=2 \vec{x}_{i}-\vec{x}_{i-1}-\frac{2 \vec{g}_{i} \cdot\left(\vec{x}_{i}-\vec{x}_{i-1}\right)}{\left|\vec{g}_{i}\right|^{2}} \vec{g}_{i}
$$

The SR-IPS runs were performed using Becke's ${ }^{26}$ threeparameter hybrid exchange functional that included the nonlocal correlation functional of Lee et al., ${ }^{27}$ denoted the B3LYP method. The all-electron $6-311+\mathrm{G}(\mathrm{d}, \mathrm{p})$ basis set was used for the B3LYP SR-IPS runs. Hence, the SR-IPS runs were performed on a B3LYP/6-311+G(d,p) PES. Generally, SR-IPS runs were performed with target isopotential hypersurface energies ranging between 325 and $450 \mathrm{~kJ} / \mathrm{mol}$ above the minimum energy structure (energy tolerance set to $\pm 5 \mathrm{~kJ} / \mathrm{mol}$ ). The maximum length of any step, in $\AA$ per active atom, was 0.02 . The potential energy surface of each molecule was computed with the Gaussian $03^{28,29}$ program package.

Once interesting reactions were identified by the B3LYP/6$311+\mathrm{G}(\mathrm{d}, \mathrm{p})$ SR-IPS runs, standard quantum chemical methods were used to analyze the unimolecular decomposition pathways with the Gaussian 03 28,29 program package. The B3LYP/6$311++\mathrm{G}(3 \mathrm{df}, 3 \mathrm{pd})$ method was used to optimize each of the stationary points (reactant, transition states, intermediates, and products) along the unimolecular decomposition pathways. Each stationary point was fully optimized and characterized by vibrational analysis as either energy minima (zero imaginary frequencies) or first-order saddle points (one imaginary frequency). Symmetry or geometrical constraints were not allowed during the energy minimizations. Default convergence criteria were used for all of the energy minimizations. Intrinsic reaction coordinate $\left(\mathrm{IRC}^{30}\right)$ calculations were performed from each transition state to verify that it properly connected the desired reactants and products. Thermodynamic functions were calculated assuming a rigid rotor/harmonic oscillator approximation and unscaled vibrational frequencies.

To obtain more reliable reaction enthalpies (at 298.15 K) and activation barriers, single-point CCSD(T) energy calculations were performed on each stationary point. Dunning's correlation consistent aug-cc-pVTZ ${ }^{31-33}$ basis set was used. The aug-ccpVTZ basis set is augmented with diffuse functions and includes $2 \mathrm{~d}$ polarization functions on hydrogen atoms and $3 \mathrm{~d} 2 \mathrm{f}$ polarization functions on carbon and nitrogen atoms. The relative enthalpies shown in Schemes 1-7 correspond to the sum of the electronic and thermal energies, which include the vibrational zero-point energies, calculated with the $\operatorname{CCSD}(\mathrm{T}) / \mathrm{aug}-\mathrm{cc}-\mathrm{pVTZ}$ and B3LYP/6-311++G(3df,3pd) methods, respectively. Therefore, the relative enthalpies of 5-ATZ and 5-ITZ unimolecular decomposition pathways shown in Schemes 1-7 were computed using the CCSD(T)/aug-cc-pVTZ//B3LYP/6-311++G(3df,3pd) level of theory.

\section{Results and Discussion}

Figure 1 depicts energy-minimized structures of $1 \mathrm{H}$-5-ATZ, 2H-5-ATZ, and 5-ITZ. The atom labels in Figure 1 are used to list selected structural parameters of the reactants, transition states (TS), intermediates, and products corresponding to the various unimolecular decomposition pathways of 5-ATZ and 5-ITZ, which can be found in Tables 1-7. In Schemes 1-7, the unimolecular decomposition pathways, as revealed by the SR-IPS runs, are shown. Each reactant, TS, intermediate, and product shown in Schemes 1-7 is labeled by a Roman numeral 
SCHEME 1: Relative Energetics (298.15 K) of 5-ITZ Unimolecular Decomposition Pathway Leading to $\mathbf{H N}_{3}$ and NHCNH Products

(II)

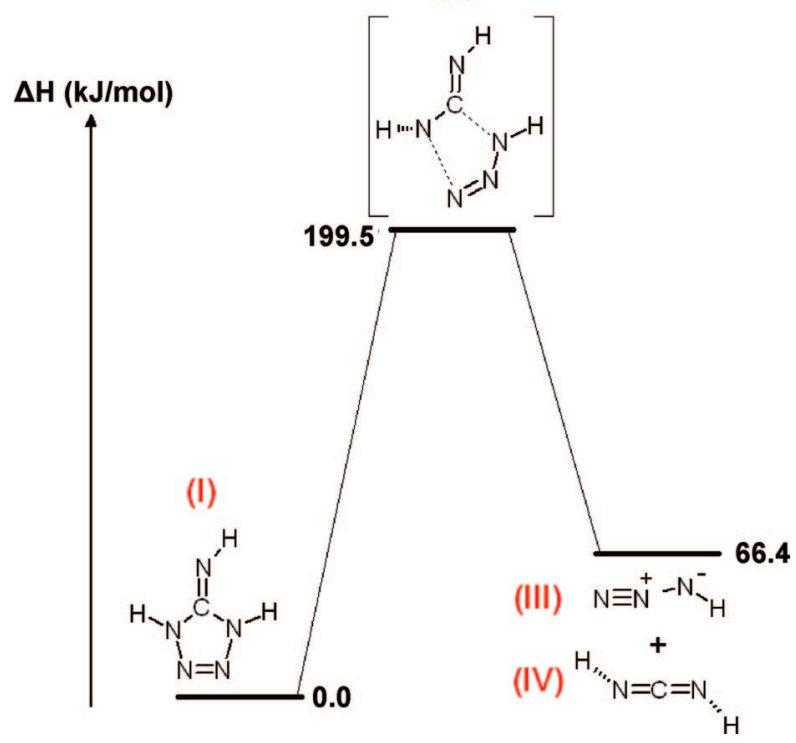

TABLE 1: Selected Structural Parameters (̊̊, deg) of each Reactant, TS, and Product for the Unimolecular Decomposition of 5-ITZ Corresponding to Scheme 1 (See Figure 1a for Atom Labels and Scheme 1 for Species Labels)

\begin{tabular}{lcccc}
\hline \multicolumn{1}{c}{ parameter } & I & II & III & IV \\
\hline C-N1 & 1.272 & 1.239 & & 1.218 \\
C-N2 & 1.383 & 1.273 & & 1.218 \\
C-N5 & 1.387 & 1.958 & & \\
N1-H1 & 1.013 & 1.009 & & 1.010 \\
N2-N3 & 1.356 & 2.030 & & \\
N2-H2 & 1.004 & 1.009 & & 1.010 \\
N3-N4 & 1.259 & 1.162 & 1.125 & \\
N4-N5 & 1.366 & 1.270 & 1.235 & \\
N5-H3 & 1.003 & 1.015 & 1.017 & \\
C-N1-H1 & 112.9 & 117.5 & & 120.1 \\
C-N2-N3 & 112.5 & 108.5 & & \\
C-N2-H2 & 126.5 & 118.0 & & 120.1 \\
C-N5-N4 & 112.1 & 103.5 & & \\
C-N5-H3 & 128.1 & 134.2 & & 170.8 \\
N1-C-N2 & 126.0 & 148.1 & & \\
N1-C-N5 & 134.9 & 114.1 & & \\
N2-C-N5 & 98.9 & 97.0 & & \\
N2-N3-N4 & 108.3 & 96.0 & & \\
N3-N2-H2 & 120.8 & 102.1 & & \\
N3-N4-N5 & 107.8 & 131.5 & 171.8 & \\
N4-N5-H3 & 119.6 & 114.7 & 110.6 &
\end{tabular}

for corresponding identification of their structural parameters listed in Tables $1-7$. As previously mentioned in the Introduction, Levchik et al. ${ }^{1}$ found that the imino tautomer, 5-ITZ, initially undergoes thermal decomposition in a sample subjected to thermal treatment. As thermal treatment continues (i.e., temperature is increased), however, an increased proportion of the amino tautomer, 5-ATZ, accumulates and in turn undergoes thermal decomposition. Between 325 and $450 \mathrm{~kJ} / \mathrm{mol}$, SR-IPS runs did not reveal unimolecular tautomerism between $1 \mathrm{H}-5$ ATZ and 5-ITZ. As this tautomerism had been shown to be important in the bulk phases, we additionally located the transition state and calculated the activation barrier corresponding to tautomerism between $1 \mathrm{H}$-5-ATZ and 5-ITZ, which was found to be $243.4 \mathrm{~kJ} / \mathrm{mol}$ at the $\operatorname{CCSD}(\mathrm{T}) /$ aug-cc-pVTZ// B3LYP/6-311++G(3df,3pd) level of theory (1H-5-ATZ was
SCHEME 2: Relative Energetics (298.15 K) of 5-ITZ Unimolecular Decomposition Pathway Leading to $\mathrm{N}_{2}$ and Metastable $\mathrm{CH}_{3} \mathrm{~N}_{3}$ Products

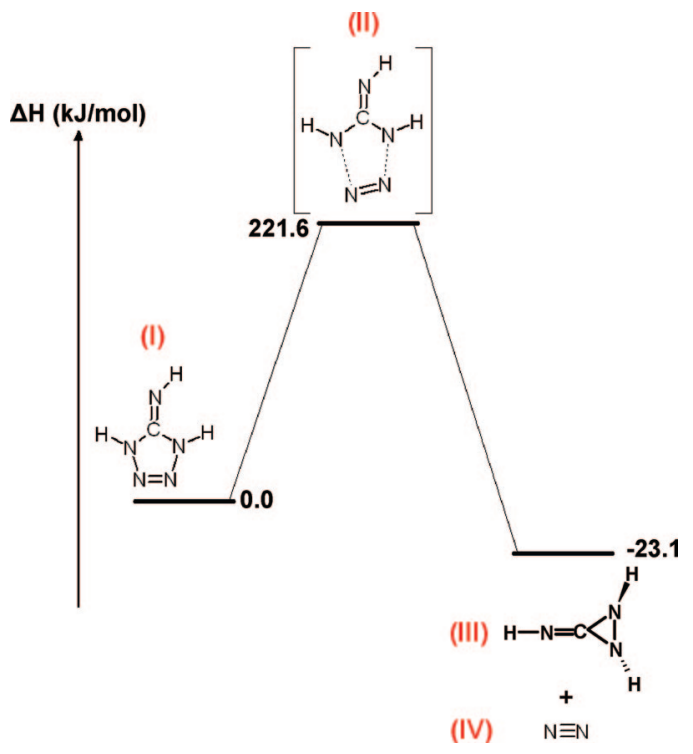

SCHEME 3: Relative Energetics (298.15 K) of 1H-5-ATZ Unimolecular Decomposition Pathway Leading to $\mathrm{HN}_{3}$ and $\mathrm{NH}_{2} \mathrm{CN}$ Products

(II)

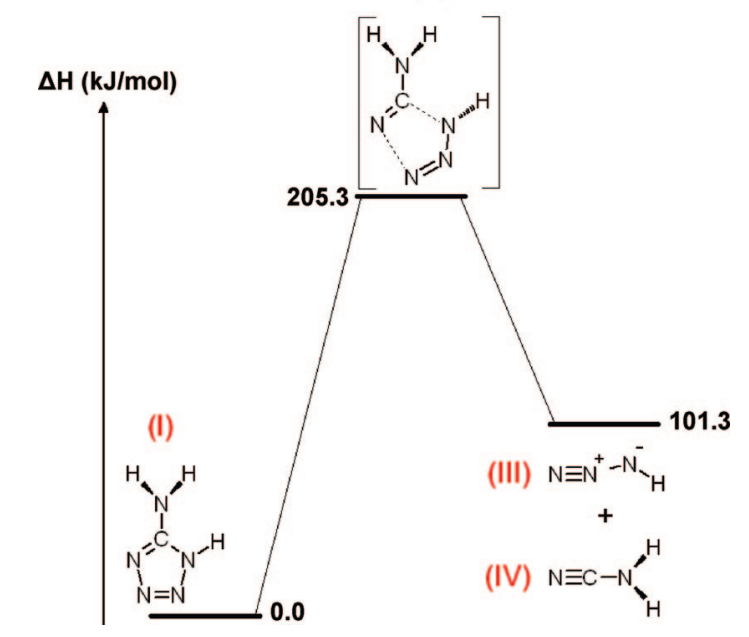

found to be $47.7 \mathrm{~kJ} / \mathrm{mol}$ more stable than 5 -ITZ in the gas phase; see Table S3 in the Supporting Information). In this section, we will first discuss the unimolecular decomposition pathways of 5-ITZ, which will be followed by a discussion of the $1 \mathrm{H}$ 5-ATZ and 2H-5-ATZ unimolecular decomposition pathways.

3.1. Unimolecular Decomposition of 5-ITZ. The unimolecular decomposition of 5-ITZ has not been previously investigated with quantum chemical methods, although Ivashkevich et al. ${ }^{34}$ determined the structures of 5-ITZ at the semiempirical level of theory and found agreement with the experimental results of Nelson and Baglin. ${ }^{16}$ To aid in determining the mechanism of 5-ITZ unimolecular decomposition, 80 SR-IPS runs were performed on isopotential hypersurfaces ranging between 325 and $450 \mathrm{~kJ} / \mathrm{mol}$. Of the $80 \mathrm{SR}$-IPS runs performed, 76 resulted in the unimolecular decomposition pathway shown in Scheme 1. The remaining four SR-IPS runs resulted in the unimolecular decomposition pathway depicted in Scheme 2. The unimolecular decomposition pathway shown in Scheme 1 involves simultaneous breaking of the N2-N3 and 
SCHEME 4: Relative Energetics $(298.15 \mathrm{~K})$ of $1 \mathrm{H}$-5-ATZ Unimolecular Decomposition Pathway Leading to $\mathrm{HN}_{3}$ and NHCNH Products

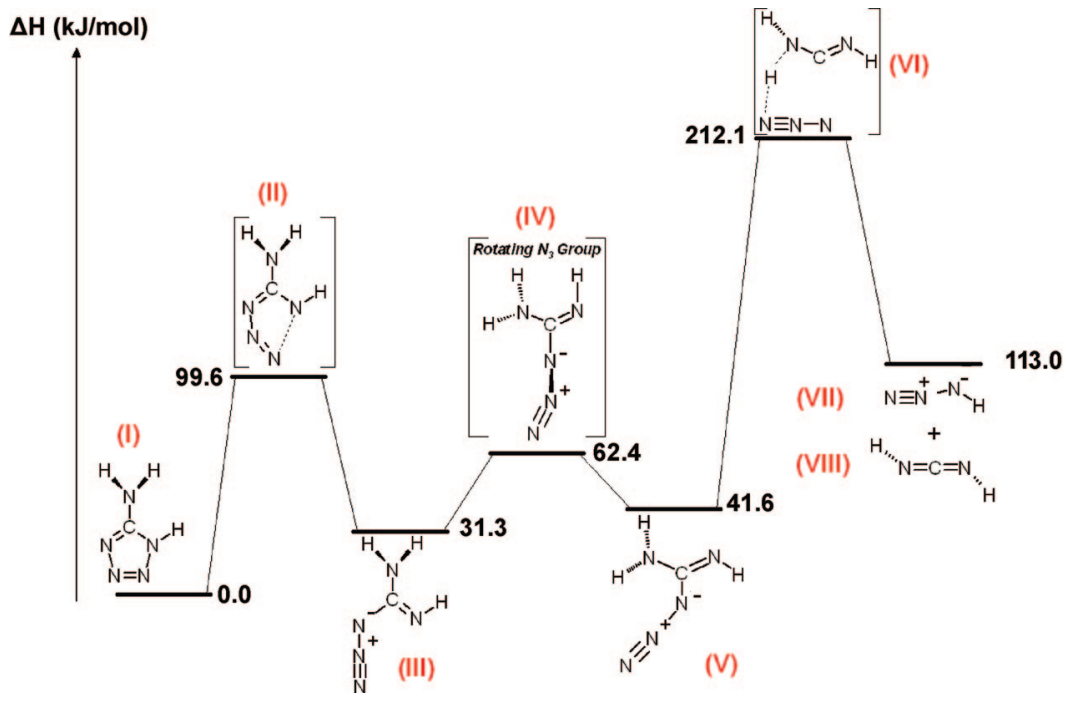

TABLE 2: Selected Structural Parameters (̊̊, deg) of each Reactant, TS, and Product for the Unimolecular Decomposition of 5-ITZ Corresponding to Scheme 2 (See Figure 1a for Atom Labels and Scheme 2 for Species Labels $)^{a}$

\begin{tabular}{lccc}
\hline \multicolumn{1}{c}{ parameter } & II & III & IV \\
\hline C-N1 & 1.328 & 1.391 & \\
C-N2 & 1.281 & 1.245 & \\
C-N5 & 1.439 & 1.377 & \\
N1-H1 & 1.017 & 1.018 & \\
N2-N3 & 2.356 & & \\
N2-H2 & 1.012 & 1.017 & \\
N3-N4 & 1.118 & & 1.091 \\
N4-N5 & 1.689 & & \\
N5-H3 & 1.018 & 1.018 & \\
C-N1-H1 & 113.5 & 112.1 & \\
C-N2-N3 & 92.0 & & \\
C-N2-H2 & 113.5 & 111.8 & \\
C-N5-N4 & 105.7 & & \\
C-N5-H3 & 113.0 & 112.4 & \\
N1-C-N2 & 135.1 & 148.9 & \\
N1-C-N5 & 105.4 & 68.8 & \\
N2-C-N5 & 117.5 & 142.1 & \\
N2-N3-N4 & 93.1 & & \\
N3-N2-H2 & 138.7 & & \\
N3-N4-N5 & 121.8 & & \\
N4-N5-H3 & 98.6 & &
\end{tabular}

${ }^{a}$ Structural parameters of I are listed in Table 1.

$\mathrm{C}-\mathrm{N} 5$ bonds. Table 1 indicates that these bond distances of 5-ITZ increase from 1.356 and $1.387 \AA$ to 2.030 and $1.958 \AA$, respectively, in the TS (II). The products of 5-ITZ unimolecular decomposition, according to Scheme 1, are $\mathrm{HN}_{3}$ (III) and NHCNH (IV). NHCNH (IV) likely isomerizes into $\mathrm{NH}_{2} \mathrm{CN} .{ }^{1,17}$ Overall, this unimolecular decomposition pathway of 5-ITZ is predicted to be endothermic $(66.4 \mathrm{~kJ} / \mathrm{mol})$ with an activation barrier equal to $199.5 \mathrm{~kJ} / \mathrm{mol}$. The activation barrier predicted at the CCSD(T)/aug-cc-pVTZ//B3LYP/6-311++G(3df,3pd) level of theory is remarkably (or fortuitously) close to the experimentally estimated activation barrier of $200 \mathrm{~kJ} / \mathrm{mol}$ for this thermal decomposition pathway. ${ }^{14}$

The unimolecular decomposition pathway of 5-ITZ depicted in Scheme 2 results in the formation of a metastable $\mathrm{CH}_{3} \mathrm{~N}_{3}$ (III) product and $\mathrm{N}_{2}$ (IV). Additional SR-IPS runs on the metastable $\mathrm{CH}_{3} \mathrm{~N}_{3}$ (III) product indicate that it readily decom-
TABLE 3: Selected Structural Parameters (̊̊, deg) of each Reactant, TS, and Product for the Unimolecular

Decomposition of $1 \mathrm{H}$-5-ATZ Corresponding to Scheme 3 (See Figure 1b for Atom Labels and Scheme 3 for Species Labels) ${ }^{a}$

\begin{tabular}{lccc}
\hline parameter & I & II & IV \\
\hline C-N1 & 1.370 & 1.360 & 1.339 \\
C-N2 & 1.315 & 1.192 & 1.154 \\
C-N5 & 1.345 & 1.917 & \\
N1-H1 & 1.008 & 1.009 & 1.009 \\
N1-H2 & 1.007 & 1.007 & 1.009 \\
N2-N3 & 1.360 & 2.096 & \\
N3-N4 & 1.277 & 1.154 & \\
N4-N5 & 1.363 & 1.276 & \\
N5-H3 & 1.005 & 1.017 & \\
C-N1-H1 & 112.7 & 113.7 & 115.5 \\
C-N1-H2 & 116.7 & 115.6 & 115.5 \\
C-N2-N3 & 105.8 & 101.2 & \\
C-N5-N4 & 108.2 & 98.6 & \\
C-N5-H3 & 131.1 & 132.2 & \\
N1-C-N2 & 126.1 & 146.9 & 177.3 \\
N1-C-N5 & 125.4 & 104.0 & \\
N2-C-N5 & 108.2 & 109.0 & \\
N2-N3-N4 & 111.8 & 96.4 & \\
N3-N4-N5 & 105.8 & 134.2 & \\
N4-N5-H3 & 120.5 & 113.3 & \\
H1-N1-H2 & 112.8 & 113.2 & 113.4
\end{tabular}

${ }^{a}$ Structural parameters of III are listed in Table 1.

poses into hydrogen isocyanide (HNC) and trans-diazine (HNNH) (data not shown). The unimolecular decomposition pathway of 5-ITZ depicted in Scheme 2 involves simultaneous breaking of the N2-N3 and N4-N5 bonds. Tables 1 and 2 indicate that these bond distances of 5-ITZ increase from 1.356 and $1.366 \AA$ to 2.356 and $1.689 \AA$, respectively, in the TS (II). Overall, this unimolecular decomposition pathway of 5-ITZ is predicted to be exothermic $(-23.1 \mathrm{~kJ} / \mathrm{mol})$ with an activation barrier equal to $221.6 \mathrm{~kJ} / \mathrm{mol}$.

Several investigators have determined that the initial primary gaseous products measured in thermal decomposition experiments of 5-ITZ are $\mathrm{HN}_{3}$ and $\mathrm{NH}_{2} \mathrm{CN}$. ${ }^{1,12-14}$ The activation barrier predicted for Scheme 1 is approximately $22 \mathrm{~kJ} / \mathrm{mol}$ lower than the activation barrier predicted for Scheme 2. This result explains why $\mathrm{HN}_{3}$ and $\mathrm{NH}_{2} \mathrm{CN}$ products are initially detected in thermal decomposition experiments, as opposed to $\mathrm{N}_{2}$ and $\mathrm{CH}_{3} \mathrm{~N}_{3}$ 
SCHEME 5: Relative Energetics $(298.15 \mathrm{~K})$ of 1H-5-ATZ Unimolecular Decomposition Pathway Leading to $\mathrm{N}_{2}$ and Metastable $\mathrm{CH}_{3} \mathrm{~N}_{3}$ Products

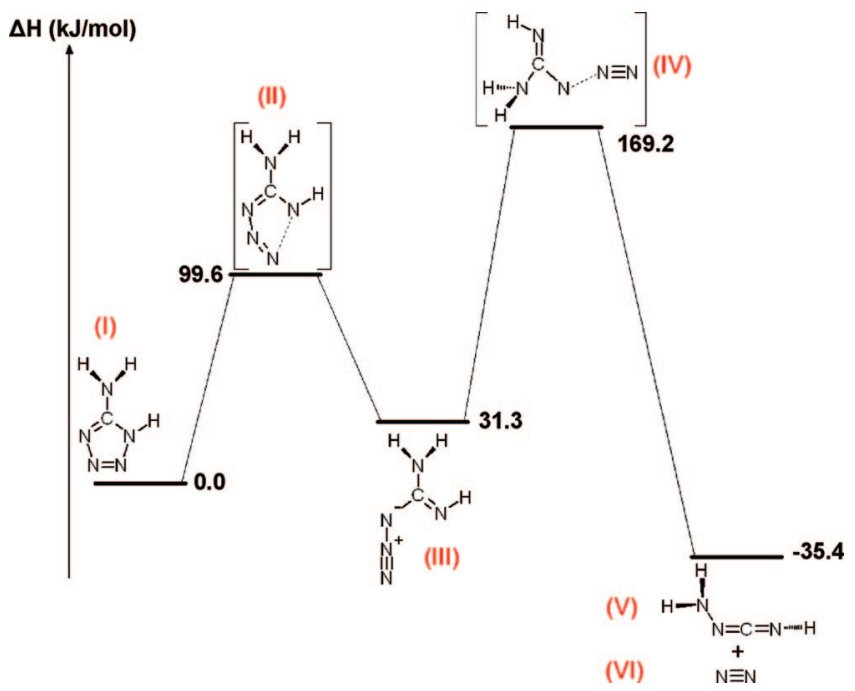

TABLE 4: Selected Structural Parameters ( $\AA$, deg) of each Reactant, TS, Intermediate, and Product for the Unimolecular Decomposition of $1 \mathrm{H}-5$-ATZ Corresponding to Scheme 4 (See Figure 1b for Atom Labels and Scheme 4 for Species Labels) ${ }^{a}$

\begin{tabular}{|c|c|c|c|c|c|}
\hline parameter & II & III & IV & V & VI \\
\hline $\mathrm{C}-\mathrm{N} 1$ & 1.361 & 1.373 & 1.378 & 1.381 & 1.272 \\
\hline $\mathrm{C}-\mathrm{N} 2$ & 1.409 & 1.421 & 1.443 & 1.428 & 2.447 \\
\hline $\mathrm{C}-\mathrm{N} 5$ & 1.278 & 1.270 & 1.262 & 1.265 & 1.202 \\
\hline N1-H1 & 1.006 & 1.006 & 1.007 & 1.008 & 1.127 \\
\hline $\mathrm{N} 1-\mathrm{H} 2$ & 1.003 & 1.004 & 1.007 & 1.008 & 1.012 \\
\hline $\mathrm{N} 2-\mathrm{N} 3$ & 1.288 & 1.236 & 1.229 & 1.233 & 1.165 \\
\hline $\mathrm{N} 3-\mathrm{N} 4$ & 1.159 & 1.120 & 1.126 & 1.126 & 1.182 \\
\hline $\mathrm{N} 4-\mathrm{N} 5$ & 2.064 & 3.343 & & & \\
\hline N4-H1 & & & & & 1.533 \\
\hline N5-H3 & 1.008 & 1.014 & 1.017 & 1.014 & 1.010 \\
\hline $\mathrm{C}-\mathrm{N} 1-\mathrm{H} 1$ & 116.0 & 117.2 & 116.9 & 117.7 & 118.4 \\
\hline $\mathrm{C}-\mathrm{N} 1-\mathrm{H} 2$ & 118.8 & 117.5 & 117.2 & 112.5 & 116.7 \\
\hline $\mathrm{C}-\mathrm{N} 2-\mathrm{N} 3$ & 104.4 & 115.1 & 116.7 & 118.4 & 89.0 \\
\hline $\mathrm{C}-\mathrm{N} 5-\mathrm{N} 4$ & 95.0 & 75.9 & & & \\
\hline $\mathrm{C}-\mathrm{N} 5-\mathrm{H} 3$ & 122.3 & 112.7 & 112.3 & 111.4 & 122.7 \\
\hline $\mathrm{N} 1-\mathrm{C}-\mathrm{N} 2$ & 113.1 & 109.2 & 111.8 & 116.2 & 97.8 \\
\hline $\mathrm{N} 1-\mathrm{C}-\mathrm{N} 5$ & 129.1 & 129.4 & 129.5 & 122.0 & 158.3 \\
\hline $\mathrm{N} 2-\mathrm{C}-\mathrm{N} 5$ & 117.6 & 121.2 & 118.5 & 121.6 & 103.1 \\
\hline $\mathrm{N} 2-\mathrm{N} 3-\mathrm{N} 4$ & 135.1 & 173.5 & 173.0 & 173.2 & 169.6 \\
\hline $\mathrm{N} 3-\mathrm{N} 4-\mathrm{N} 5$ & 87.7 & 41.2 & & & \\
\hline $\mathrm{N} 4-\mathrm{N} 5-\mathrm{H} 3$ & 142.4 & 171.2 & & & \\
\hline $\mathrm{H} 1-\mathrm{N} 1-\mathrm{H} 2$ & 116.5 & 116.1 & 114.9 & 113.5 & 112.9 \\
\hline
\end{tabular}

products (or the secondary decomposition products of $\mathrm{CH}_{3} \mathrm{~N}_{3}$ ). Nevertheless, the unimolecular decomposition pathway of 5-ITZ shown in Scheme 2 could be viable under conditions in which its larger activation barrier (compared to Scheme 1) is rapidly exceeded (e.g., very high heating rate).

3.2. Unimolecular Decomposition of $1 H-5-\mathrm{ATZ}$ and $2 \mathrm{H}$ 5-ATZ. Levchik et al. ${ }^{1}$ argued that $1 H$-5-ATZ and $2 H$-5-ATZ prototropic tautomerism could occur in the melt phase. Thus, we performed SR-IPS runs for both the $1 \mathrm{H}$-5-ATZ and $2 \mathrm{H}-5$ ATZ tautomers of 5-ATZ (see Figure 1). SR-IPS runs for $1 H$ 5-ATZ revealed three unique unimolecular decomposition pathways leading to a variety of reaction products. These unimolecular decomposition pathways are shown in Schemes $3-5$. The unimolecular decomposition pathway shown in
SCHEME 6: Relative Energetics (298.15 K) of 2H-5-ATZ Unimolecular Decomposition Pathway Leading to $\mathrm{HN}_{3}$ and $\mathrm{NH}_{2} \mathrm{CN}$ Products

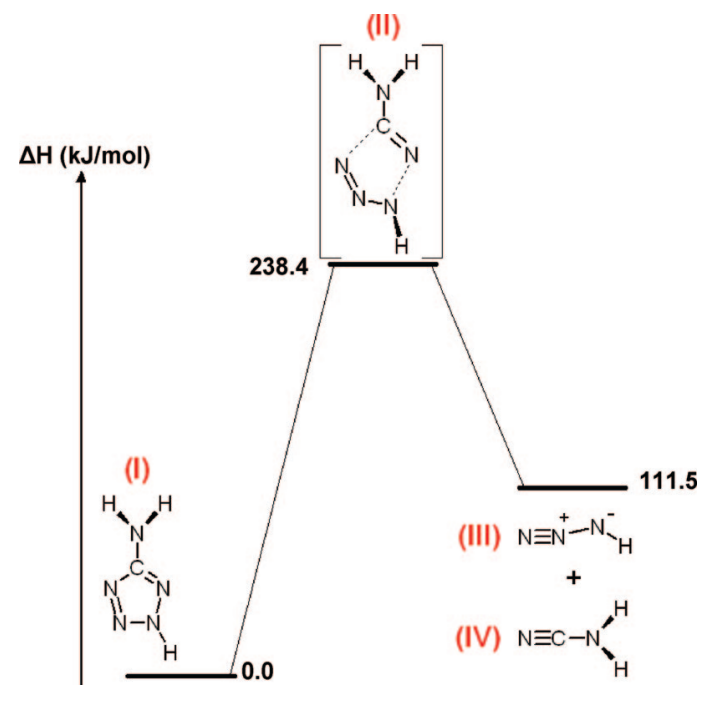

SCHEME 7: Relative Energetics (298.15 K) of 2H-5-ATZ Unimolecular Decomposition Pathway Leading to $\mathrm{N}_{2}$ and Metastable $\mathrm{CH}_{3} \mathrm{~N}_{3}$ Products

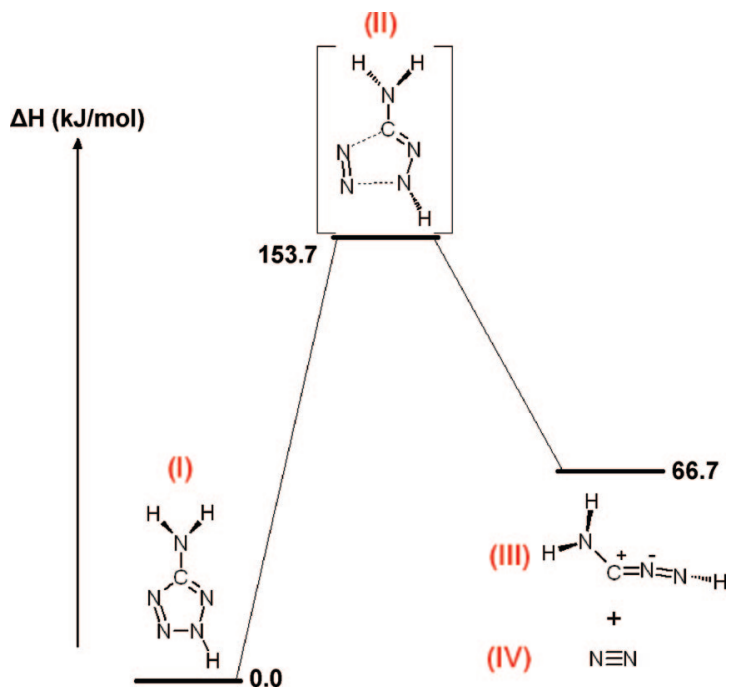

Scheme 3 involves simultaneous breaking of the N2-N3 and $\mathrm{C}-\mathrm{N} 5$ bonds. This particular unimolecular decomposition pathway of $1 H-5-\mathrm{ATZ}$ was recently investigated by Zhang et al., ${ }^{23}$ and is also analogous to pathways for the synthesis of tetrazole studied by Cheng. ${ }^{22}$ Table 3 indicates that these bond distances of $1 H$-5-ATZ increase from 1.360 and $1.345 \AA$ to 2.096 and $1.917 \AA$, respectively, in the TS (II). These distances are in good agreement with those calculated by Zhang et al. ${ }^{23}$ and Cheng ${ }^{22}$ where both used the B3LYP method with a large basis set. The products of $1 \mathrm{H}$-5-ATZ unimolecular decomposition, according to Scheme 3, are $\mathrm{HN}_{3}$ (III) and $\mathrm{NH}_{2} \mathrm{CN}$ (IV). Overall, this unimolecular decomposition pathway of $1 H-5-\mathrm{ATZ}$ is predicted to be endothermic $(101.3 \mathrm{~kJ} / \mathrm{mol})$ with an activation barrier equal to $205.3 \mathrm{~kJ} / \mathrm{mol}$. The reaction enthalpy and activation barrier predicted at the $\operatorname{CCSD}(\mathrm{T}) /$ aug-cc-pVTZ// B3LYP/6-311++G(3df,3pd) level of theory are in good agreement with the theoretical study performed by Zhang et al., ${ }^{23}$ although they used a smaller basis set.

Several SR-IPS runs of $1 \mathrm{H}-5$-ATZ revealed the interesting unimolecular decomposition pathway shown in Scheme 4, which 
TABLE 5: Selected Structural Parameters (Å, deg) of each Reactant, TS, Intermediate, and Product for the Unimolecular Decomposition of $1 \mathrm{H}-5$-ATZ Corresponding to Scheme 5 (See Figure 1b for Atom Labels and Scheme 5 for Species Labels) ${ }^{a}$

\begin{tabular}{|c|c|c|}
\hline parameter & IV & V \\
\hline $\mathrm{C}-\mathrm{N} 1$ & 1.463 & \\
\hline $\mathrm{C}-\mathrm{N} 2$ & 1.329 & 1.217 \\
\hline $\mathrm{C}-\mathrm{N} 5$ & 1.266 & 1.227 \\
\hline $\mathrm{N} 1-\mathrm{N} 2$ & & 1.412 \\
\hline $\mathrm{N} 1-\mathrm{H} 1$ & 1.011 & 1.011 \\
\hline $\mathrm{N} 1-\mathrm{H} 2$ & 1.011 & 1.016 \\
\hline $\mathrm{N} 2-\mathrm{N} 3$ & 1.797 & \\
\hline N3-N4 & 1.094 & \\
\hline N5-H3 & 1.014 & 1.014 \\
\hline $\mathrm{C}-\mathrm{N} 1-\mathrm{H} 1$ & 113.6 & \\
\hline $\mathrm{C}-\mathrm{N} 1-\mathrm{H} 2$ & 113.7 & \\
\hline $\mathrm{C}-\mathrm{N} 2-\mathrm{N} 1$ & & 124.5 \\
\hline $\mathrm{C}-\mathrm{N} 2-\mathrm{N} 3$ & 106.1 & \\
\hline $\mathrm{C}-\mathrm{N} 5-\mathrm{H} 3$ & 110.4 & 117.1 \\
\hline $\mathrm{N} 1-\mathrm{C}-\mathrm{N} 2$ & 95.8 & \\
\hline $\mathrm{N} 1-\mathrm{C}-\mathrm{N} 5$ & 128.2 & \\
\hline $\mathrm{N} 2-\mathrm{C}-\mathrm{N} 5$ & 135.9 & 169.7 \\
\hline $\mathrm{N} 2-\mathrm{N} 3-\mathrm{N} 4$ & 152.6 & \\
\hline $\mathrm{N} 2-\mathrm{N} 1-\mathrm{H} 1$ & & 105.9 \\
\hline $\mathrm{N} 2-\mathrm{N} 1-\mathrm{H} 2$ & & 110.0 \\
\hline $\mathrm{H} 1-\mathrm{N} 1-\mathrm{H} 2$ & 110.6 & 107.8 \\
\hline
\end{tabular}

${ }^{a}$ Structural parameters of I are listed In Table 3. Structural parameters of II and III are listed in Table 4. Structural parameters of VI are listed in Table 2.

TABLE 6: Selected Structural Parameters (̊̊, deg) of each Reactant, TS, and Product for the Unimolecular Decomposition of $2 \mathrm{H}$-5-ATZ Corresponding to Scheme 6 (See Figure 1c for Atom Labels and Scheme 6 for Species Labels $)^{a}$

\begin{tabular}{lcc}
\hline parameter & I & II \\
\hline $\mathrm{C}-\mathrm{N} 1$ & 1.368 & 1.347 \\
$\mathrm{C}-\mathrm{N} 2$ & 1.359 & 1.928 \\
$\mathrm{C}-\mathrm{N} 5$ & 1.326 & 1.200 \\
$\mathrm{~N} 1-\mathrm{H} 1$ & 1.006 & 1.005 \\
$\mathrm{~N} 1-\mathrm{H} 2$ & 1.006 & 1.006 \\
$\mathrm{~N} 2-\mathrm{N} 3$ & 1.307 & 1.170 \\
$\mathrm{~N} 3-\mathrm{N} 4$ & 1.311 & 1.252 \\
$\mathrm{~N} 4-\mathrm{N} 5$ & 1.335 & 2.091 \\
$\mathrm{~N} 4-\mathrm{H} 3$ & 1.007 & 1.019 \\
$\mathrm{C}-\mathrm{N} 1-\mathrm{H} 1$ & 114.6 & 116.9 \\
$\mathrm{C}-\mathrm{N} 1-\mathrm{H} 2$ & 115.6 & 117.2 \\
$\mathrm{C}-\mathrm{N} 2-\mathrm{N} 3$ & 106.1 & 98.2 \\
$\mathrm{C}-\mathrm{N} 5-\mathrm{N} 4$ & 100.5 & 98.3 \\
$\mathrm{~N} 1-\mathrm{C}-\mathrm{N} 2$ & 122.8 & 102.8 \\
$\mathrm{~N} 1-\mathrm{C}-\mathrm{N} 5$ & 124.5 & 145.4 \\
$\mathrm{~N} 2-\mathrm{C}-\mathrm{N} 5$ & 112.5 & 111.5 \\
$\mathrm{~N} 2-\mathrm{N} 3-\mathrm{N} 4$ & 106.0 & 134.9 \\
$\mathrm{~N} 3-\mathrm{N} 4-\mathrm{N} 5$ & 114.8 & 95.4 \\
$\mathrm{~N} 3-\mathrm{N} 4-\mathrm{H} 3$ & 122.4 & 113.7 \\
$\mathrm{~N} 5-\mathrm{N} 4-\mathrm{H} 3$ & 122.7 & 113.9 \\
$\mathrm{H} 1-\mathrm{N} 1-\mathrm{H} 2$ & 114.4 & 116.3
\end{tabular}

${ }^{a}$ Structural parameters of III are listed in Table 1. Structural parameters of IV are listed in Table 3.

has not been previously determined within its entirety in the literature. As shown in Scheme 4, the N4-N5 bond first breaks to form an open-ring intermediate (III) of $1 H$-5-ATZ. Tables 3 and 4 indicate that the $\mathrm{N} 4-\mathrm{N} 5$ bond distance increases from 1.363 to $2.064 \AA$, while the N2-N3-N4 bond angle increases from 111.8 to $135.1^{\circ}$, in the TS (II). From this TS (II) to the first intermediate (III), the N4-N5 distance further increases from 2.064 to $3.343 \AA$, while the N2-N3-N4 bond angle
TABLE 7: Selected Structural Parameters (̊̊, deg) of each Reactant, TS, and Product for the Unimolecular Decomposition of $2 \mathrm{H}-5$-ATZ Corresponding to Scheme 7 (See Figure 1c for Atom Labels and Scheme 7 for Species Labels) ${ }^{a}$

\begin{tabular}{lcc}
\hline parameter & II & III \\
\hline C-N1 & 1.339 & 1.338 \\
C-N2 & 1.760 & \\
C-N5 & 1.249 & 1.207 \\
N1-H1 & 1.006 & 1.002 \\
N1-H2 & 1.009 & 1.009 \\
N2-N3 & 1.146 & \\
N3-N4 & 2.005 & 1.250 \\
N4-N5 & 1.290 & 1.025 \\
N4-H3 & 1.021 & 118.8 \\
C-N1-H1 & 116.8 & 121.6 \\
C-N1-H2 & 119.2 & 160.7 \\
C-N2-N3 & 111.9 & \\
C-N5-N4 & 123.2 & 133.8 \\
N1-C-N2 & 119.1 & \\
N1-C-N5 & 134.8 & \\
N2-C-N5 & 104.5 & \\
N2-N3-N4 & 101.1 & 108.1 \\
N3-N4-N5 & 96.6 & 116.9 \\
N3-N4-H3 & 118.4 & \\
N5-N4-H3 & 110.3 & \\
H1-N1-H2 & 115.1 &
\end{tabular}

${ }^{a}$ Structural parameters of I are listed in Table 6. Structural parameters of IV are listed in Table 2.

becomes nearly linear (increase from 135.1 to $173.5^{\circ}$ ). A second intermediate $(\mathrm{V})$ is formed by rotation of the $\mathrm{N}_{3}$ fragment approximately $180^{\circ}$ about the $\mathrm{C}-\mathrm{N} 2$ bond axis. The $\mathrm{N}_{3}$ fragment then detaches from the second intermediate (V), whereby the unimolecular decomposition pathway progresses through another TS (VI) that involves $\mathrm{C}-\mathrm{N} 2$ bond breaking (see Scheme 4 and Table 4). In this TS (VI), the $\mathrm{N}_{3}$ fragment abstracts a hydrogen atom from the $\mathrm{NH}_{2}$ group and the final reaction products are $\mathrm{HN}_{3}$ (VII) and $\mathrm{NHCNH}$ (VIII). Again, $\mathrm{NHCNH}$ (VIII) likely isomerizes into $\mathrm{NH}_{2} \mathrm{CN} .{ }^{1,17}$ Ring opening for a series of tetrazole derivatives has been studied theoretically by Zhao-Xu and Heming. ${ }^{19}$ The TS structure of the ring opening step was only reported for 5-chloro-tetrazole because the authors maintain that the TS geometries are sufficiently similar to justify this simplification. The fact that their analogous 5-chlorotetrazole TS structure has a N4-N5 bond distance of $2.072 \AA$ (compared to our value of $2.064 \AA$ for $1 H-5-\mathrm{ATZ}$ ) and N2-N3-N4 angle of 134.7 (compared to our value of 135.1) lends this contention credence. Although not reported specifically within the tables, it is interesting to note that planarity of the tetrazole ring is maintained during the ring opening step, also in agreement with previous calculations.

It is interesting to note that the reaction enthalpies and overall activation barriers of Schemes 3 and 4 are predicted to be quite similar. Although Levchik et al. ${ }^{1}$ showed that the thermal decomposition products of 5-ATZ (not 5-ITZ) are $\mathrm{N}_{2}$ and metastable $\mathrm{CH}_{3} \mathrm{~N}_{3}$, the unimolecular decomposition pathways shown in Schemes 3 and 4 could be viable under high heating rates (see discussion below). Under such conditions, the unimolecular decomposition pathways of $1 \mathrm{H}$-5-ATZ shown in Schemes 3 and 4 would be competitive.

The third unimolecular decomposition pathway of $1 H-5-\mathrm{ATZ}$, as revealed by the SR-IPS runs, is shown in Scheme 5. The first three steps are identical to Scheme 4, namely, the formation of an open-ring intermediate (III) of $1 H$-5-ATZ. Note that the predicted activation barrier to form the open-ring intermediate 
in Schemes 4 and 5, $99.6 \mathrm{~kJ} / \mathrm{mol}$, is in remarkable agreement with Zhao-Xu and Heming's ${ }^{19}$ predicted activation barrier of $99.5 \mathrm{~kJ} / \mathrm{mol}$ at the B3LYP/6-31G(d) level of theory. In contrast to Scheme 4, however, the second TS (IV) of Scheme 5 involves breaking of the $\mathrm{N} 2-\mathrm{N} 3$ bond. Tables 4 and 5 indicate that the $\mathrm{N} 2-\mathrm{N} 3$ bond distance increases from 1.236 to $1.797 \AA$, while the N3-N4 bond distance decreases from 1.120 to $1.094 \AA$, in the TS (IV). The products of $1 H-5$-ATZ unimolecular decomposition, according to Scheme 5, are $\mathrm{CH}_{3} \mathrm{~N}_{3}(\mathrm{~V})$ and $\mathrm{N}_{2}(\mathrm{VI})$. Note that the metastable $\mathrm{CH}_{3} \mathrm{~N}_{3}$ product, from species IV to species V in Scheme 5, undergoes a barrierless rearrangement ( $\mathrm{NH}_{2}$ transfer to undercoordinated $\mathrm{N}$ atom).

The unimolecular decomposition pathway of $1 H-5-\mathrm{ATZ}$ shown in Scheme 5 is similar to the most favorable unimolecular decomposition pathway of 5-nitro- $1 \mathrm{H}$-tetrazole revealed by the AIMD simulations of Wang et al. ${ }^{18}$ Wang et al. ${ }^{18}$ reasoned that the formation of an open-ring intermediate of 5-nitro- $1 \mathrm{H}$ tetrazole, similar to species III in Scheme 5, represents the main unimolecular decomposition pathway leading to $\mathrm{N}_{2}$ formation. It was additionally shown that bond breaking of the 5-nitro$1 H$-tetrazole ring could occur between the carbon and nitrogen atom not bonded to a hydrogen atom. As expected, however, the activation energy was predicted to be very high $(305.8 \mathrm{~kJ} /$ mol at the $\operatorname{CCSD}(\mathrm{T}) / 6-31 \mathrm{G}(\mathrm{d}, \mathrm{p}) / / \mathrm{B} 3 \mathrm{LYP} / 6-31 \mathrm{G}(\mathrm{d})$ level of theory). ${ }^{18}$ Between 325 and $450 \mathrm{~kJ} / \mathrm{mol}$, SR-IPS runs did not reveal bond breaking between the $\mathrm{C}$ and $\mathrm{N} 2$ atoms of $1 \mathrm{H}-5$ ATZ. Nevertheless, for completeness, calculations were performed to locate the transition state of this $\mathrm{C}-\mathrm{N} 2$ bond breaking event, and the activation barrier was found to be $305.5 \mathrm{~kJ} / \mathrm{mol}$ at the $\operatorname{CCSD}(\mathrm{T}) /$ aug-cc-pVTZ//B3LYP/6-311++G(3df,3pd) level of theory.

In the gas phase, our calculations indicated that $2 H-5-\mathrm{ATZ}$ is $10.1 \mathrm{~kJ} / \mathrm{mol}$ more stable than $1 H-5-\mathrm{ATZ}$ at the $\operatorname{CCSD}(\mathrm{T}) /$ aug-cc-pVTZ//B3LYP/6-311++G(3df,3pd) level of theory (see Table S3 in the Supporting Information), which is in accordance with previous theoretical results. Chen et al. ${ }^{21}$ found the $2 \mathrm{H}$ 5-ATZ structure to be $15.1 \mathrm{~kJ} / \mathrm{mol}$ lower in energy at the B3LYP/6-31+G(d) level of theory. Using the B3LYP/6$311++\mathrm{G}(\mathrm{d}, \mathrm{p})$ level of theory, Sadlej-Sosnowska ${ }^{35}$ also calculated that $2 \mathrm{H}$-5-ATZ is more stable than $1 \mathrm{H}-5$-ATZ in the gas phase $(15.1 \mathrm{~kJ} / \mathrm{mol}$, zero-point correction not applied). Moreover, Wong et al..$^{36}$ determined that $2 \mathrm{H}$-tetrazole, compared to $1 \mathrm{H}$-tetrazole, is the energetically preferred tautomer in the gas phase, using a variety of quantum chemical methods. For $2 \mathrm{H}$ 5-ATZ, we performed 60 SR-IPS runs on isopotential hypersurfaces ranging between 325 and $450 \mathrm{~kJ} / \mathrm{mol}$. Of the $60 \mathrm{SR}-$ IPS runs performed, two resulted in the unimolecular decomposition pathway shown in Scheme 6. The remaining 58 SR-IPS runs resulted in the unimolecular decomposition pathway depicted in Scheme 7.

The unimolecular decomposition pathway shown in Scheme 6 involves simultaneous breaking of the $\mathrm{C}-\mathrm{N} 2$ and $\mathrm{N} 4-\mathrm{N} 5$ bonds. Table 6 indicates that these bond distances of $2 \mathrm{H}-5$ ATZ increase from 1.359 and $1.335 \AA$ to 1.928 and $2.091 \AA$, respectively, in the TS (II). The products of $2 \mathrm{H}-5-\mathrm{ATZ}$ unimolecular decomposition, according to Scheme 6, are $\mathrm{HN}_{3}$ (III) and $\mathrm{NH}_{2} \mathrm{CN}$ (IV). Overall, this unimolecular decomposition pathway of $2 \mathrm{H}-5$-ATZ is predicted to be endothermic (111.5 $\mathrm{kJ} / \mathrm{mol}$ ) with an activation barrier equal to $238.4 \mathrm{~kJ} / \mathrm{mol}$. Note that the reaction enthalpies and overall activation barriers of Schemes 3, 4, and 6 are predicted to be quite similar for $1 H$ 5-ATZ and 2H-5-ATZ.

The unimolecular decomposition pathway shown in Scheme 7 involves simultaneous breaking of the $\mathrm{C}-\mathrm{N} 2$ and $\mathrm{N} 3-\mathrm{N} 4$ bonds. Tables 6 and 7 indicate that these bond distances of $2 \mathrm{H}$ 5-ATZ increase from 1.359 and $1.311 \AA$ to 1.760 and $2.005 \AA$, respectively, in the TS (II). The products of $2 H-5-\mathrm{ATZ}$ unimolecular decomposition, according to Scheme 7, are a metastable $\mathrm{CH}_{3} \mathrm{~N}_{3}$ (III) fragment and $\mathrm{N}_{2}$ (IV). Overall, this unimolecular decomposition pathway of $2 \mathrm{H}$-5-ATZ is predicted to be endothermic $(66.7 \mathrm{~kJ} / \mathrm{mol})$ with an activation barrier equal to $153.7 \mathrm{~kJ} / \mathrm{mol}$.

According to Levchik et al., ${ }^{1}$ the initial gaseous products of 5-ATZ (not 5-ITZ) thermal decomposition are primarily $\mathrm{N}_{2}$ and metastable $\mathrm{CH}_{3} \mathrm{~N}_{3}$. Furthermore, Lesnikovich et al. ${ }^{14}$ estimated that the apparent activation energy for this process is approximately $150 \mathrm{~kJ} / \mathrm{mol}$. At the CCSD(T)/aug-cc-pVTZ//B3LYP/ $6-311++\mathrm{G}(3 \mathrm{df}, 3 \mathrm{pd})$ level of theory, our predicted activation barriers for Schemes 5 and 7 are equal to 169.2 and $153.7 \mathrm{~kJ} /$ mol, respectively, which are in very reasonable agreement with those of Lesnikovich et al. ${ }^{14}$ Most importantly, the predicted activation barriers for Schemes 5 and 7 are significantly lower than the activation barriers predicted for Schemes 3, 4, and 6 (205.3, 212.1, and $238.4 \mathrm{~kJ} / \mathrm{mol}$, respectively). Therefore, in agreement with our theoretical results, the unimolecular decomposition products of Schemes 5 and $7\left(\mathrm{~N}_{2}\right.$ and metastable $\mathrm{CH}_{3} \mathrm{~N}_{3}$ ) would be initially detected in a thermal decomposition experiment with reasonable heating rates (e.g., Levchik et al. ${ }^{1}$ ).

\section{Conclusions}

The unimolecular decomposition of 5-ATZ and its tautomer 5-ITZ were investigated at the CCSD(T)/aug-cc-pVTZ//B3LYP/ $6-311++\mathrm{G}(3 \mathrm{df}, 3 \mathrm{pd})$ level of theory. For 5-ATZ, the unimolecular decomposition of both $1 H$-5-ATZ and $2 H$-5-ATZ were investigated. As the principal focus of this study dealt with unimolecular decomposition, and not the interconversion between these tautomers, is it merely noted that the relative energetics of $1 \mathrm{H}$ - and $2 \mathrm{H}$-5-ATZ and 5-ITZ were in accordance with previous theoretical work. The SR-IPS algorithm was used to reveal the various unimolecular decomposition pathways. Some of these pathways had been investigated previously within the literature, while others are presented here for the first time. The energetics and structures within the unimolecular decomposition pathways presented here agree well with previous theoretical results performed within the family of C-substituted tetrazoles. Subsequent thermodynamic analysis of the relative activation barrier energies revealed that 5-ITZ and 5-ATZ unimolecular decomposition initially results in $\mathrm{HN}_{3}$ and $\mathrm{NH}-$ $\mathrm{CNH}$ (which isomerizes into $\mathrm{NH}_{2} \mathrm{CN}$ ) reaction products and $\mathrm{N}_{2}$ and $\mathrm{CH}_{3} \mathrm{~N}_{3}$ reaction products, respectively. Our theoretical gasphase results are in excellent qualitative agreement with previous experimental studies describing the thermal decomposition of solid-state 5-ATZ and 5-ITZ under increasing temperature. An extended theoretical analysis of these reactions including the role of bulk-phase interactions is warranted and is left to future work. The energetics of the various unimolecular decomposition pathways are found to vary significantly according to the protonation state of the reactant. Therefore, we strongly encourage the use of IPS algorithms to effectively identify reasonable unimolecular decomposition reactions without foreknowledge of their reaction products.

Acknowledgment. The authors are grateful to the Army Environmental Quality Technology Program for financial support. This research was performed while K.W.P. held a National Research Council Research Associateship Award at the Army Research Laboratory. All calculations were performed at the ARL and AFRL Major Shared Resource Centers of the 
Department of Defense High Performance Computing Modernization Program. The authors also wish to thank the referees for helpful comments.

Supporting Information Available: Tables of the energyminimized Cartesian coordinates, vibrational frequencies, rotational constants, total electronic energies from CCSD(T)/augcc-pVTZ single-point energy calculations, and thermal corrections to enthalpies from B3LYP/6-311++G(3df,3pd) energy minimizations for each reactant, intermediate, TS, and product. This material is available free of charge via the Internet at http://pubs.acs.org.

\section{References and Notes}

(1) Levchik, S. V.; Ivashkevich, O. A.; Balabanovich, A. I.; Lesnikovich, A. I.; Gaponik, P. N.; Costa, L. Thermochim. Acta 1992, 207, 115.

(2) Highsmith, T. K.; Lund, G. K.; Blau, R. J.; Hinshaw, J. C.; Doll, D. W. U.S. Patent 5516377, 1996.

(3) Lund, G. K.; Blau, R. J. U.S. Patent 5500059, 1996.

(4) Poole, D. R. U.S. Patent 5035757, 1991.

(5) Ramaswarmy, C. P.; Grzelczyk, C. U.S. Patent 5661261, 1997.

(6) Wood, J. C.; Wood, E. H. U.S. Patent 6328830, 2001.

(7) Neidert, J. B.; Scheffee, R. S.; Bowman, G. T.; Martin, J. D. U.S. Patent 6228192, 2001. 98,197

(8) Williams, G. K.; Palopoli, S. F.; Brill, T. B. Combust. Flame 1994,

(9) Steinhauser, G.; Klapötke, T. M. Angew. Chem., Int. Ed. 2008, 47, 3330 .

(10) Brady, L. E. J. Heterocycl. Chem. 1970, 7, 1223.

(11) Reimlinger, H. Chem. Ind. 1972, 1, 294.

(12) Brill, T. B.; Ramanathan, H. Combust. Flame 2000, 122, 165.

(13) Gao, A.; Oyumi, Y.; Brill, T. B. Combust. Flame 1991, 83, 345

(14) Lesnikovich, A. I.; Ivashkevich, O. A.; Levchik, S. V.; Balabanovich, A. I.; Gaponik, P. N.; Kulak, A. A. Thermochim. Acta 2002, 388, 233.

(15) Jonassen, H. B.; Paukert, T.; Henry, R. A. Appl. Spectrosc. 1967, $21,89$.

(16) Nelson, J. H.; Baglin, F. G. Spectrosc. Lett. 1972, 5, 101.

(17) Kurzer, F.; Douraghi-Zadeh, K. Chem. Rev. 1967, 67, 107.

(18) Wang, J.; Gu, J.; Tian, A. Chem. Phys. Lett. 2002, 351, 459.

(19) Zhao-Xu, C.; Heming, X. Int. J. Quantum Chem. 2000, 79, 350.
(20) ZhaoXu, C.; Heming, X.; Shulin, Y. Chem. Phys. 1999, 250, 243.

(21) Chen, Z. X.; Xiao, J. M.; Xiao, H. M.; Chiu, Y. N. J. Phys. Chem. A 1999, 103, 8062 .

(22) Cheng, C. Int. J. Quantum Chem. 2000, 80, 27.

(23) Zhang, J.-G.; Feng, L.-N.; Zhang, S.-W.; Zhang, T.-L.; Zheng, H.H. J. Mol. Model. 2008, 14, 403.

(24) Irikura, K. K.; Johnson, R. D., III. J. Phys. Chem. A 2000, 104, 2191.

(25) Irikura, K. K.; Johnson, R. D., III. J. Phys. Chem. A 2006, 110, 13974.

(26) Becke, A. D. J. Chem. Phys. 1993, 98, 5648.

(27) Lee, C. T.; Yang, W. T.; Parr, R. G. Phys. Rev. B 1988, 37, 785.

(28) Frisch, M. J.; Trucks, G. W.; Schlegel, H. B.; Scuseria, G. E.; Robb, M. A.; Cheeseman, J. R.; Montgomery, J. A., Jr.; Vreven, T.; Kudin, K. N.; Burant, J. C.; Millam, J. M.; Iyengar, S. S.; Tomasi, J.; Barone, V.; Mennucci, B.; Cossi, M.; Scalmani, G.; Rega, N.; Petersson, G. A.; Nakatsuji, H.; Hada, M.; Ehara, M.; Toyota, K.; Fukuda, R.; Hasegawa, J.; Ishida, M.; Nakajima, T.; Honda, Y.; Kitao, O.; Nakai, H.; Klene, M.; Li, X.; Knox, J. E.; Hratchian, H. P.; Cross, J. B.; Bakken, V.; Adamo, C.; Jaramillo, J.; Gomperts, R.; Stratmann, R. E.; Yazyev, O.; Austin, A. J.; Cammi, R.; Pomelli, C.; Ochterski, J. W.; Ayala, P. Y.; Morokuma, K.; Voth, G. A.; Salvador, P.; Dannenberg, J. J.; Zakrzewski, V. G.; Dapprich, S.; Daniels, A. D.; Strain, M. C.; Farkas, O.; Malick, D. K.; Rabuck, A. D.; Raghavachari, K.; Foresman, J. B.; Ortiz, J. V.; Cui, Q.; Baboul, A. G.; Clifford, S.; Cioslowski, J.; Stefanov, B. B.; Liu, G.; Liashenko, A.; Piskorz, P.; Komaromi, I.; Martin, R. L.; Fox, D. J.; Keith, T.; Al-Laham, M. A.; Peng, C. Y.; Nanayakkara, A.; Challacombe, M.; Gill, P. M. W.; Johnson, B.; Chen, W.; Wong, M. W.; Gonzalez, C.; Pople, J. A. Gaussian 03, revision D.01; Gaussian, Inc.: Wallingford CT, 2004.

(29) Certain commercial materials and equipment are identified in this paper in order to specify procedures completely. In no case does such identification imply recommendation or endorsement by the National Institute of Standards and Technology.

(30) Gonzalez, C.; Schlegel, H. B. J. Phys. Chem. 1990, 94, 5523.

(31) Dunning, T. H., Jr. J. Chem. Phys. 1989, 90, 1007.

(32) Kendall, R. A.; Dunning, T. H., Jr.; Harrison, R. J. J. Chem. Phys. 1992, 96, 6796.

(33) Woon, D. E.; Dunning, T. H., Jr. J. Chem. Phys. 1993, 98, 1358.

(34) Ivashkevich, O. A.; Gaponik, P. N.; Koren, A. O.; Bubel, O. N.; Fronchek, E. V. Int. J. Quantum Chem. 1992, 43, 813.

(35) Sadlej-Sosnowska, N. J. Org. Chem. 2001, 66, 8737.

(36) Wong, M. W.; Leung-Toung, R.; Wentrup, C. J. Am. Chem. Soc. 1993, 115, 2465

JP810359T 